laconic. In testimonials naturally the best is made of the subject, whereas in school reports the reverse is by no means uncommon. Testimonials are not always easy to write, but the recipient need not make use of any that he does not like.

One of the best examples of a testimonial we remember to have read was given by a man to his servant. It ran somewhat in this style: "- has been my servant for six months. Anyone thinking of employing him in a similar capacity would do well to remember Mr. Punch's advice concerning matrimony." But no one ever wrote a better personal testimonal than the awful Miss Pinkerton of Chiswick Mall. She, it will be remembered, recommended Miss Tuffin and Miss Hankey for the post of governess in the family of Sir Huddleston Fuddleston. "Either was perfectly qualified to instruct in Greek, Latin, and the rudiments of Hebrew ; in mathematics and history; in Spanish, French, Italian and geography; in music, vocal and instrumental; in dancing, without the aid of a master; and in the elements of natural sciences." Miss Tuffin could also instruct "in the Syriac language and the elements of constitutional law." She was only eighteen years of age and of exceedingly pleasing personal appearance. Miss Hankey, on the other hand, was twenty-nine years of age, not personally well-looking, her face much pitted with the small-pox. She had a halt in her gait, red hair and a trifling obliquity of vision. Mr. Squeers's manifesto on the educational advantages offered at Dotheboys' Hall has always struck us as the best example of recommendation for an inanimate "thing."

\title{
ABSTRACTS
}

\section{MEDICAL OPHTHALMOLOGY}

(1) Fink, W. H. (Minneapolis, Minnesota).-The ocular pathology of methyl-alcohol poisoning. Amer. Jl. Ophthal., Vol. XXVI, p. 694, 1943.

(1) Fink comments on the lack of precise knowledge about the toxic action of methyl alcohol. It is, as yet, not clear whether the toxic effects on the central nervous system, the liver and kidneys are due to methyl alcohol itself or to its break-down products formaldehyde and formic acid, or to a combination of methyl alcohol and these products, or possibly to some other poison at present unknown.

Clinical and experimental work have shown that methyl alcohol

- enters the system through ingestion, inhalation, and is absorbed by the skin. Personal idiosyncrasy plays an important part and man seems more susceptible to this poison than animals. Oxidation is 
slow and only partial. It is possible that acidosis plays an aetiological rôle in methyl-alcohol poisoning. Elimination of the drug is slow and chiefly through the lungs. It is evident that it possesses a selective affinity for the most highly differentiated nerve elements of man.

The subjective symptoms of methyl alcohol poisoning are a sudden diminution of vision which may be of marked degree. This is followed by gradual improvement in a few weeks, and later by gradual loss of vision which may progress to total blindness. The author explains this by suggesting that there is immediate oedema of certain central ganglion cells and nerve fibres, also the papilla and retro-ocular part of the optic nerve in some cases. The oedema subsides but later some of the cells die as a result of impaired nutrition. Vision depends upon the number of cells which survive.

Scotomata may be single or multiple, a central scotoma being the most constant finding. Frequently there is peripheral contraction of the field which varies greatly in degree and position.

Ocular tenderness on pressure and on movement of the globe is evidence of an ocular or retro-bulbar congestion or oedema.

The author discusses the experimental work of 9 investigators. Three of these failed to find any evidence of histological changes in the retina and optic nerve after the administration of methyl alcohol to experimental animals. The changes described by some of the workers many years ago have been attributed to post-mortem changes and artefacts due to incorrect fixation and staining preparations.

A summary of the work shows that retinal changes predominate, choroidal vessels are congested, the entire retina is oedematous, especially the nerve fibre and ganglion cell layers. The retinal ganglion cells showed marked degeneration, the inner and outer nuclear layers are less affected. This degeneration is patchy and scattered throughout the retina. Degenerative changes are also present in the optic nerves, these are found immediately behind the eyeball and also vary in degree in their patchy distribution.

The author's own experimental work on animals showed the following changes in acute poisoning. Early chromatolysis, vacuolization of the cytoplasm of the large ganglion cells and practically complete disappearance of Nissl substance was evident. In severe cases some disintegration of the layer of rods and cones and oedema of the papilla were present. In the cases of chronic poisoning the above changes wore more marked, the disintegration of the rods and cones was more severe and the ganglion cells were reduced to shadow forms. From the histological changes it seemed that the animals reacted similarly to pure methyl alcohol, commercial methyl alcohol and to formic acid.

The author describes the general symptoms and the post-mortem changes in the tissues of the body affected by methyl alcohol.

\section{H. B. Stallard.}

